\title{
Influence of arch bridge skewness
}

\author{
Hans De Backer*,a, Amelie Outtier ${ }^{\mathrm{a}}$, Evy Van Puymbroeck*,a ${ }^{\text {, }}$ Philippe Van Bogaert ${ }^{\mathrm{a}}$ \\ ${ }^{a}$ Ghent University, Dept. of Civil Engineering, Belgium \\ Hans.DeBacker@,UGent.be
}

\begin{abstract}
This article performs a parameter study on a detailed finite element model of a simple arch bridge consisting of a single arch. The objective is to investigate the influence of different hanger arrangements, dimensions and finally a variation of the angle of skewness between the arch axis and longitudinal bridge deck axis. The influence on the stresses, forces and bending moments in the bridge deck girders, hangers and arch is examined. Finally, a buckling analysis is performed on all different models and the change in critical buckling load is discussed.

The displacements in the bridge deck stay the same for small angles of skewness. Starting from an angle of $\pm 13^{\circ}$, the position of maximum deflection in the bridge deck shifts towards the ends of the bridge deck instead of being situated staying in the middle. This can be explained by the influence of the wind load acting on the arch structure and the direction of the horizontal resultants of the hanger forces. This can cause partial relaxation, thus ensuring a small uplift at the longitudinal girders of the bridge deck. This is also the cause for the higher displacements in the arch. The torsion effect in the arch results in a counter clockwise rotation of the arch. When performing a buckling analysis on the changing angle of skewness, it is found that this initially has only a small impact on the critical load factor.
\end{abstract}

Keywords: tied-arch, buckling, steel, Eurocode, stability, design.

\section{INTRODUCTION}

Nowadays, bridges are generally constructed out of steel, concrete or a combination of both. The components which have to bear mostly compression stresses are preferably made with concrete, avoiding tensile stresses, while the structural elements in tension are constructed out of steel, avoiding buckling problems. This fundamental choice of materials, combined with the type of bridge has a major influence on the bridge design and the actual behaviour. An arch bridge is generally used for medium span bridges. Most arch bridges consist out of two parallel arches connected with each other by wind bracings in order to safely bear the transversal loads. A single arch does not have this characteristic and has to rely on a stiff connection of the arch with the bridge deck in the transversal direction. A skew placement could help to bring a solution for this problem.

A skew placement of an arch bridge is a rather modern bridge design so not many bridges of this type have been constructed. Since this is a new design concept, the amount of research on this topic is rather small. Most of the research on arch bridges focus on an arch bridge consisting out of two parallel arches.

To have the largest buckling load, parabolic arches are chosen above catenary arches or circular arches, which has been investigated by Austin and Ross [1]. But not only the arch form has a large influence, also the rise-to-span ratio is an important parameter in arch bridge design. Most arch bridges have a ratio between 0.1 and 0.5 . For which a small ratio corresponds to a large horizontal trust at the arch springs and a large ratio to a heavier construction. For a special-shape arch bridge the influence of this parameter is investigated by [2] and found that the optimal value lies in the neighbourhood of 0.35 for which this value corresponds to a maximum value of the stability coefficient. The rise-to-span ratio is also an important factor for the buckling capacity of an arch. According to Chao Dou et al. (2014), a bigger rise-to-span ratio (in the range of 0.025 to 0.25 ) results in a smaller axial force in the arch so the tendency of buckling is reduced. The buckling behaviour of 
an arch is strongly depending on the arch length. When the arch has a bigger rise, a longer arch is associated and a smaller critical buckling load is obtained.

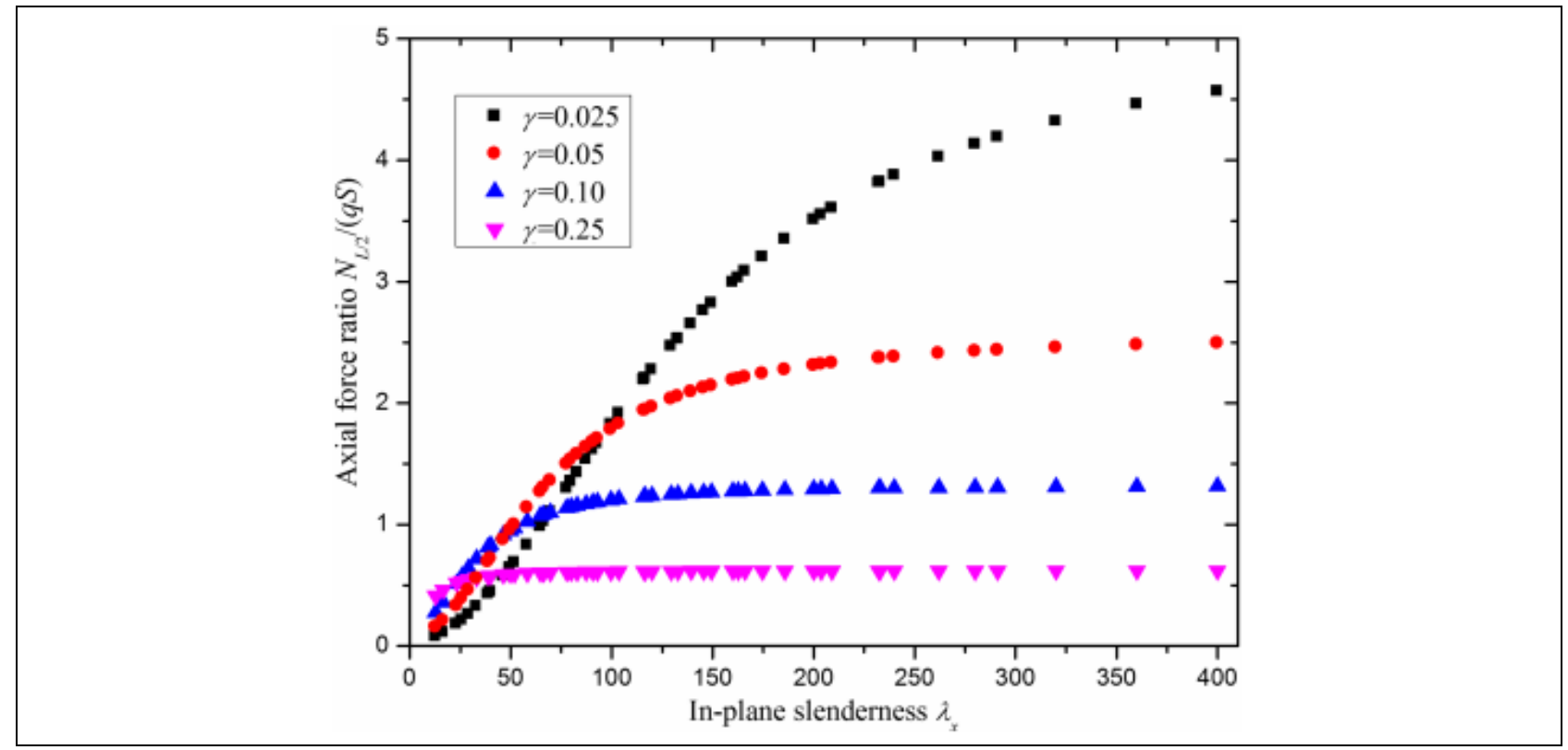

Fig. 1. The influence of the slenderness of the arch cross-section on the axial force in the arch

Another aspect investigated by Chao Dou et al. [3] is the influence of the slenderness of the arch cross-section on the axial force in the arch. A cross-section associated with a larger slenderness, gives a larger axial force in the arch and thus buckling can happen easier. Both of the conclusions made by Chao Dou et al. [3] are shown in Fig. 1.

\section{REFERENCE BRIDGE DESIGN}

In the parametric study, the influence of every parameter is investigated in accordance with the reference design. This means that only this parameter has an impact on the results. The study starts with an arch bridge with a span of $90 \mathrm{~m}$ and a width equal to $9 \mathrm{~m}$, shown in Fig. 2. This circular arch has a height of $25 \mathrm{~m}$, which results in a rise-to-span ratio of 0.278 . The cross-section of the arch is a rectangle with a web height and flange width of $1500 \mathrm{~mm}$ and a flange- and web thickness of $45 \mathrm{~mm}$. The hangers are able to sustain a design force of $2385 \mathrm{kN}$.

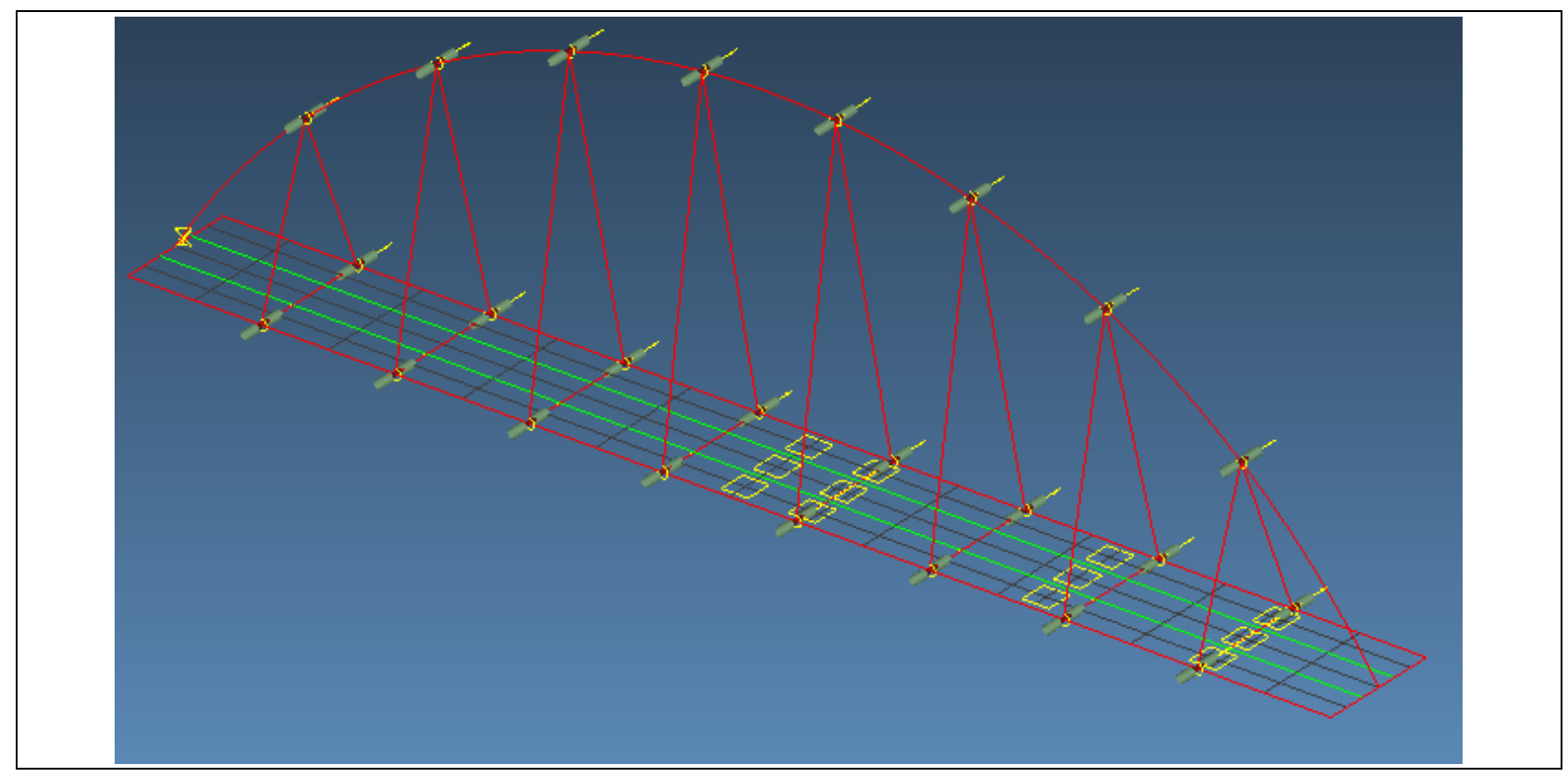

(C) Ernst \& Sohn Verlag für Architektur und technische Wissenschaften GmbH \& Co. KG, Berlin · CE/papers (2017) 
The two arch springs are modelled as clamped constraints and do not sustain any movements and rotations. The bridge deck is supported in the vertical direction at both ends. The longitudinal movements of the deck are restraints at one side and tolerated at the other. The movements in the transverse direction are restraint at only one side of the end beams.

To have relevant results, it is important to start with a realistic design. That's why some elements of this model are verified and compared to realistic arch behaviour.

\section{PARAMETRIC STUDY}

\subsection{Width of the bridge deck}

The elongation of the cross-girders from $9 \mathrm{~m}$ to $19 \mathrm{~m}$ in steps of $1 \mathrm{~m}$, result in a bigger dead load of the bridge deck and in a larger surface on which all loads can be applied. The longer length of the beams gives larger deflections and bending moments so the yield strength and elastic moment of the girders are easily reached. The rise in tension in the cables is linear with the widening of the bridge deck. Of course, the extra forces acting in the hangers are brought to the arch structure, which leads the loads to its springs. The stresses in the arch undergo a raise, especially in the arch. The normal forces in the arch have to be smaller than the buckling force. This only results in collapse by buckling for bridges wider than $19 \mathrm{~m}$. The buckling behaviour of the arch gives a first buckling mode which is associated with a half-sine function formed out of the arch plane. The critical load factor for a $9 \mathrm{~m}$ wide bridge deck has a value of 10.04, what means that all loads can be multiplied by this factor before buckling occurs. This factor decreases to 7.33 when the deck is widened to $19 \mathrm{~m}$.

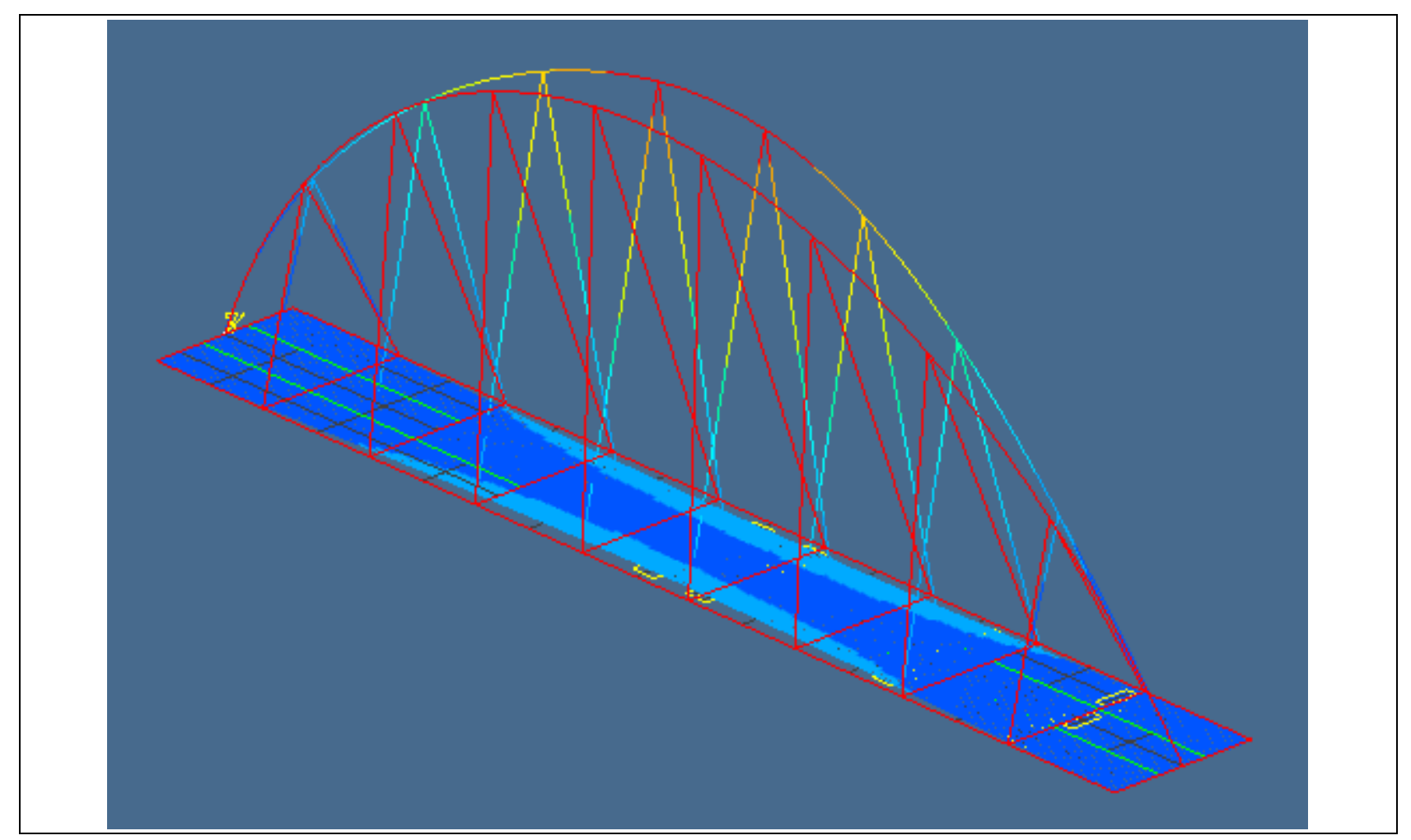

Fig. 3. First buckling mode

\subsection{Rise-to-span ratio}

As already stated in the literature study, the rise-to-span ratio has a large influence on the behaviour of the arch bridge. The displacements in the arch and bridge deck have a parabolic distribution, so an optimum value can be found which has a magnitude of 0.2 . The cable stresses decrease when a larger ratio is applied. The explanation in this development can be found in the angle between the bridge deck and the cable. Not only the displacements have a parabolic behaviour, also the stresses in the arch tend to behave in that way. Again, an optimum value can be found. The minimum tensile stresses

(C) Ernst \& Sohn Verlag für Architektur und technische Wissenschaften GmbH \& Co. KG, Berlin · CE/papers (2017) 
in the arch occur at a rise-to-span ratio of 0.15 while the minimum pressure stresses happen at a ratio of 0.25 . A changing rise-to-span ratio is associated with a changing arch length, which has a large influence on the critical buckling behaviour of the arch. When comparing the normal forces in the arch, it can be seen that the out-of-plane buckling behaviour is more critical than the in-plane behaviour. Which corresponds to what is stated in previous sections. Another important consequence of the changing height of the arch is the direction of the resulting force vector at the arch springs. When constructing a lower arch, the impact of the horizontal trust will be much more important than the vertical resultant. An important remark here is that the second buckling mode is not an out-ofplane full sine, but an in-plane buckling mode for very low arches. This is because a lower arch will tend to behave like a horizontal beam, which has a critical buckling mode in its plane.

\subsection{Arch cross-section}

The deflections in the bridge deck as well as in the arch top decrease when installing a thicker arch cross-section. Because of the increased moment of inertia in the arch, the displacements and bending moments in the arch decrease. The larger surface of the cross-section corresponds to a decrease in the stresses in the arch, but with an increasing force as result because of the larger dead load of the arch. The increasing normal force is not a threat to the buckling behaviour of the arch because with the increasing moment of inertia, the critical buckling load has a steeper increase. The critical load factor of the arch also increases when applying a thicker flange- and web thickness of the arch. The influence on the stresses in the bridge deck is minor when compared to the stress differences in the arch. The thickness of the arch doesn't have a direct influence on the bridge deck.

\subsection{Skewness angle and hanger arrangement}

The displacements in the bridge deck stay the same for small angles of skewness. It is starting from an angle of $\pm 13^{\circ}$, that the position of maximum deflection in the bridge deck shifts towards the end of the bridge deck instead of staying in the middle. This is explained by the direction of the wind load acting upon the arch structure and the direction of the horizontal resultant of the hanger force vector. When both of these act in the same direction, the hanger will be more relaxed than when the horizontal resultant of the hangers is opposite to the wind loads. This results in a smaller uplift at the longitudinal girders of the bridge deck. The torsion effect in the arch results in a counter clockwise rotation of the arch. When performing a buckling analysis on the changing angle of skewness, it is found that this actually only has a small impact on the critical load factor. So, placing the arch in a skewed position over the bridge deck does not mean that the arch will be submitted to an extra buckling load.

Different cable configurations are investigated to look for an optimal situation. These configurations are combined with 5 load models. Four different cable arrangements are investigated to look for the optimum amount of cables and to have sufficient available height for traffic. The first configuration uses cables at each intersection between the cross-girders and the longitudinal girders connected to the arch at equal horizontal distances. This configuration results in strong restrictions to the traffic height. The second configuration connects all cables to the inner $50 \%$ of the arch length. Not all crossgirder ends are being connected. The cables, which would cross the complete bridge deck in a rotated situation, are removed. This is also the case for configuration 3 and 4 . In configuration 3 , the cables are kept perpendicular in the horizontal plane to the longitudinal girder whereas in configuration 4 , the cables are always connected perpendicular to the arch.

The normal forces in the arch increase when approaching the arch springs, as shown in Fig. 4. The different jumps in the graph are located at the positions where hangers are attached. The bigger the hanger force, the bigger the jump. An important aspect of the skew placed arch are the direction of the hangers. These hangers pull the arch out of its plane, so large vertical bending moment around the vertical axis can be observed. The higher the angle of skewness, the bigger this effect and the higher the clamping moments at the arch springs. 


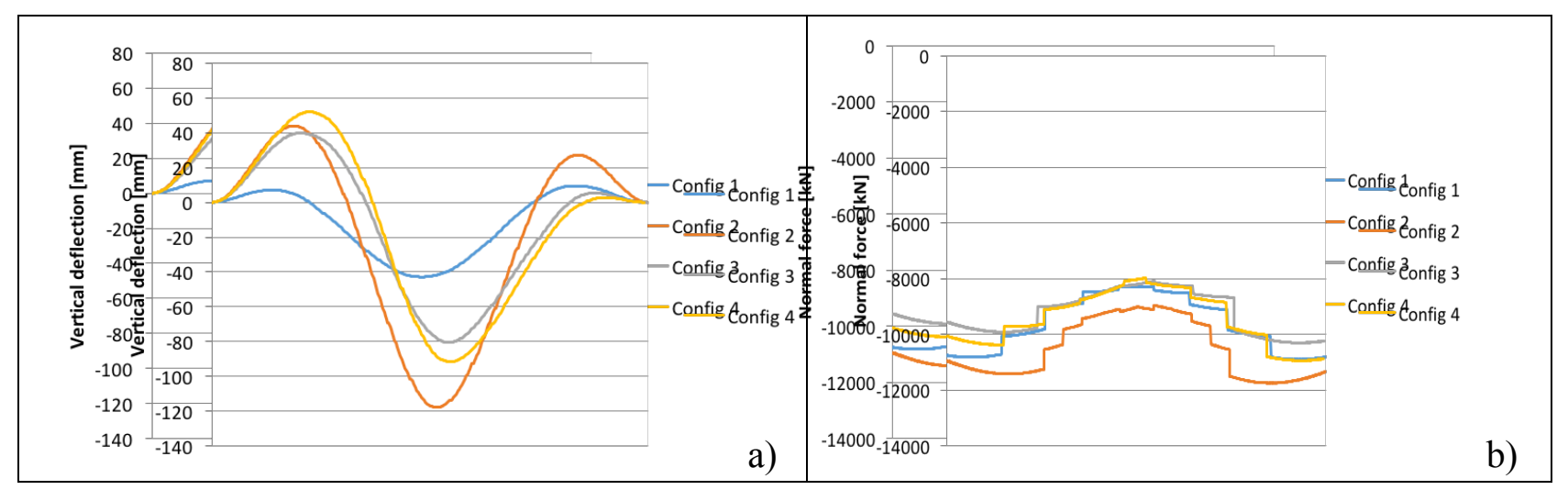

Fig. 1. a) Vertical deflections for different hanger configurations;

b) Normal forces in the arch for different hanger configurations

When looking at the critical buckling load of the different configurations, only small differences can be observed when using the same load model and angle of skewness. When changing the angle of skewness, some changes can be noticed. When increasing the angle from $0^{\circ}$ to $20^{\circ}$, only minor differences occur. But when increasing the angle up to $40^{\circ}$, a strong decrease up to $30 \%$ can be noticed. An important difference between the difference configurations is the number of hangers and location of the hangers. In configuration 1, 16 hangers are applied whereas for configuration 3 only 8. It is obvious that the stress in the hangers in configuration 3 will have to bear higher stresses since the same bridge deck has to be supported. In configuration 1 and 2, no difficulties with regard to pressure in the hangers can be found. This is not the case for configuration 3 and 4 . Once a hanger is under pressure, it does not contribute to the system.

\section{CONCLUSIONS}

As already mentioned in the literature study, the rise-to-span ratio has an important impact on the bridge design. An optimal value of the ratio can be found in the range of $0.20-0.25$. The stresses, deflections and forces in the deck and arch display a minimum value at this ratio. A widening bridge deck mostly influences the stresses in the transverse girders in the bridge deck. Reinforcement of these beams will be necessary. The extra dead load and applied loads on the deck result in extra hanger stresses and larger stresses in the arch structure as well. Changing the wall thickness of the arch results in smaller stresses and bending moments in the arch, but goes hand in hand with an increase of the dead load of the arch, larger normal forces will appear. The problem of the extra load and dead load also has a major influence on a longer bridge span. The longer the span, the larger the stresses in the arch. A stronger arch will be needed. Changing the skewness of the arch only has an influence on the end zones of the bridge deck. Extra deflections and stresses are observed in these sections. The buckling mode of an arch bridge stays the same for all models and show a half-sine function out of its plane. The critical load factor does not keep a constant value. The changing span decreases the load factor largely. The load factor for a changing rise-to-span ratio again shows an optimum value for a ratio of approximately 0.25 . The angle of skewness does not have a major influence, so no buckling problems should be expected.

\section{REFERENCES}

[1] Austin, W.-J. and Ross, T.-J., "Elastic Buckling of Arches under Symmetrical Loading”, Journal of Structural Division, ASCE, 102, 1085-1095, 1976

[2] Wen-Liang, Q., Chin-Sheng, K. et al., "Stability Analysis of Special-Shape Arch Bridge", Tamkang Journal of Science and Engineering, 13(4), 365-373, 2010

[3] Chao, D., Yan-Lin, G., Yong-Lin, P. and Si-Yuan, Z., "Flexural-Torsional Buckling and Ultimate Resistance of Parabolic Steel Arches Subjected to Uniformly Distributed Vertical Load", American Society of Civil Engineers, 2014 